\title{
RESEARCH
}

Open Access

\section{Significance of a preoperative systemic immune-inflammation index as a predictor of postoperative survival outcomes in gastric cancer}

Hiroyuki Inoue ${ }^{1}$, Toshiyuki Kosuga ${ }^{1,2^{*}}$ (D), Takeshi Kubota ${ }^{1}$, Hirotaka Konishi ${ }^{1}$, Atsushi Shiozaki ${ }^{1}$, Kazuma Okamoto $^{1}$, Hitoshi Fujiwara ${ }^{1}$ and Eigo Otsuji

\begin{abstract}
Background: Since inflammation and the immune system contribute to the development and progression of malignancies, parameters that reflect a host's immune-inflammatory status may be useful prognostic indicators of gastric cancer (GC). The present study examined the clinical significance of a preoperative systemic immuneinflammation index (SII) for predicting postoperative survival outcomes in GC.

Methods: A total of 447 patients who underwent curative gastrectomy for GC were included in the present study. SII was calculated as platelet count $\times$ neutrophil count/lymphocyte count. The prognostic impact of preoperative SIl was examined using univariate and multivariate analyses.

Results: Preoperative SII ranged between 105 and 4455 (median 474), and the optimal cutoff value for predicting overall survival (OS) was 395 based on a receiver operating characteristic curve. The 5-year OS rate of the SII $\geq 395$ group was $80.0 \%$, which was significantly worse than that $(92.7 \%)$ of the $\mathrm{SIl}<395$ group $(p<0.001)$. The multivariate analysis identified SII $\geq 395$ (hazard ratio [HR] 2.95; 95\% confidence interval [Cl] 1.49-6.39; $p=0.001$ ), heart disease (HR 2.14, 95\% Cl 1.07-4.07), C-reactive protein $\geq 0.5$ (HR 2.45, 95\% Cl 1.15-4.94), pT4 (HR 4.46, 95\% Cl 2.44-8.14), and $\mathrm{pN}+(\mathrm{HR} 4.02,95 \% \mathrm{Cl} 2.10-7.93)$ as independent predictors of worse OS. Peritoneal recurrence was more frequent in the high SII group than in the low SII group $(p=0.028)$.

Conclusion: Preoperative SII may be a useful predictor of postoperative survival outcomes in GC. The meticulous surveillance of GC relapse, particularly peritoneal dissemination, is necessary for patients with SII $\geq 395$ even after curative gastrectomy.
\end{abstract}

Keywords: Gastric cancer, Systemic immune-inflammation index, Gastrectomy, Prognosis

\footnotetext{
* Correspondence: toti-k@koto.kpu-m.ac.jp

1 Division of Digestive Surgery, Department of Surgery, Kyoto Prefectural University of Medicine, 465 Kajii-cho, Kamigyo-ku, Kyoto 602-8566, Japan

${ }^{2}$ Department of Surgery, Saiseikai Shiga Hospital, Ritto, Shiga, Japan
}

(c) The Author(s). 2021 Open Access This article is licensed under a Creative Commons Attribution 4.0 International License, which permits use, sharing, adaptation, distribution and reproduction in any medium or format, as long as you give appropriate credit to the original author(s) and the source, provide a link to the Creative Commons licence, and indicate if changes were made. The images or other third party material in this article are included in the article's Creative Commons licence, unless indicated otherwise in a credit line to the material. If material is not included in the article's Creative Commons licence and your intended use is not permitted by statutory regulation or exceeds the permitted use, you will need to obtain permission directly from the copyright holder. To view a copy of this licence, visit http://creativecommons.org/licenses/by/4.0/. The Creative Commons Public Domain Dedication waiver (http://creativecommons.org/publicdomain/zero/1.0/) applies to the data made available in this article, unless otherwise stated in a credit line to the data. 


\section{Background}

Gastric cancer (GC) is the sixth most common cancer and the second leading cause of cancer-related death worldwide [1]. Despite the recent advances in surgical procedures and chemotherapy, recurrence is still reported in a large number of patients with GC even after curative resection. Therefore, to improve the survival outcomes of GC, it is important to identify patients with a high risk of GC recurrence who need to be treated with adequate adjuvant treatments and meticulous surveillance even after curative gastrectomy.

Since inflammation and the immune system contribute to the development and progression of malignancies [2, 3], parameters that reflect a host's immune-inflammatory status may be useful prognostic indicators of GC. Neutrophil (Neut), lymphocyte (Lymp), monocyte (Mono), and platelet (Plt) counts in the peripheral blood were previously shown to be convenient and helpful prognostic indicators of GC [4-6]. A systemic immune-inflammation index (SII), readily calculated by the combination of three complete blood count $(\mathrm{CBC})$ parameters (Neut, Lymp, and Plt), has recently been attracting increasing attention as a powerful prognostic indicator in several malignancies, such as esophageal, colon, and pancreatic cancers [7-9]; however, the clinical utility of SII in GC remains unclear.

In the present study, the clinical significance of preoperative SII for predicting the postoperative survival outcomes of GC was compared with that of each $\mathrm{CBC}$ parameter (Neut, Lymp, Mono, or Plt). The relationship between preoperative SII and the type of GC recurrence was also examined. The aim of the present study was to establish a novel perioperative care system according to preoperative SII levels.

\section{Methods}

\section{Patients}

A total of 447 patients who underwent surgery for GC between January 2008 and June 2013 at the Kyoto Prefectural University of Medicine were included in the present study. The inclusion criteria were as follows: (1) patients pathologically diagnosed with gastric adenocarcinoma; (2) patients with pathological stages (pStage) I, II, and III; and (3) patients undergoing the curative resection of GC (R0). Patients who received neoadjuvant chemotherapy; those who underwent emergency surgery; those who underwent non-curative resection (R1/R2); those with hematological, chronic inflammatory, or autoimmune diseases that may affect preoperative SII values; and those with active infection or inflammatory diseases within 1 month before the blood examination were excluded. Patients with missing information on preoperative $\mathrm{CBC}$ and those with simultaneous malignancies other than GC were also excluded. Gastrectomy with lymph node dissection was performed based on the
Japanese Gastric Cancer Treatment Guidelines (JGCTG) [10]. Tumor staging was performed according to the 8th edition of the Tumor, Node, Metastasis staging classification by the Union for International Cancer Control [11]. In the present study, grade 2 or higher postoperative complications according to the Clavien-Dindo Classification $[12,13]$ occurred in 60 patients $(13.4 \%)$, and only one patient $(0.22 \%)$ died of postoperative complications.

All patients provided written informed consent before surgery. The present study was approved by the Ethics Committee of the Kyoto Prefectural University of Medicine (approval no. ERB-C-1327).

\section{Data collection of preoperative CBC and SII}

Preoperative CBC (Neut, Lymp, Mono, and Plt) was collected from patients within 7 days before surgery, and SII was calculated as Plt $\left(\right.$ cell $\left./ \mathrm{mm}^{3} \times 10^{3}\right) \times$ Neut $\left(\right.$ cell $\left./ \mathrm{mm}^{3}\right) /$ Lymp $\left(\right.$ cell $\left./ \mathrm{mm}^{3}\right)$.

\section{Clinicopathological findings}

The following clinicopathological data were reviewed from the medical record database of our institution: age, sex, body mass index (BMI), physical status (PS), comorbidities (hypertension, diabetes mellitus, heart disease, and chronic renal failure), tumor location, preoperative serum carcinoembryonic antigen (CEA), cancer antigen (CA) 19-9, albumin, C-reactive protein (CRP), preoperative CBC (Neut, Lymp, Mono, and Plt), pathological $\mathrm{T}$ stage $(\mathrm{pT})$, pathological $\mathrm{N}$ stage $(\mathrm{pN})$, lymphatic invasion, venous invasion, and tumor differentiation.

\section{Adjuvant treatment and postoperative follow-up}

After curative gastrectomy for GC, patients with pStage I generally received postoperative examinations alone without any adjuvant treatments. Patients with pStage II and III were basically treated with adjuvant chemotherapy based on JGCTG. The main chemotherapeutic regimens administered were S-1 alone [14], S-1 plus oxaliplatin (SOX) [15], or capecitabine plus oxaliplatin (CapeOX) [16], in line with JGCTG [10]. All patients were followed up at regular intervals with serum CEA and CA19-9; computed tomography (CT) of the chest, abdomen, and pelvis; and upper gastrointestinal endoscopy following the JGCTG. Most patients were postoperatively followed up for 5 years or until their death. GC recurrence was confirmed by imaging, such as CT and upper gastrointestinal endoscopy. If possible, recurrence was histologically confirmed via surgical biopsy, needle biopsy, or appropriate fluid cytology. Peritoneal recurrence was diagnosed by imaging alone, and diagnostic laparotomy was rarely performed.

\section{Statistical analysis}

Differences between the two groups for categorical and continuous variables were analyzed by the chi-squared 
test and Mann-Whitney U test, respectively. The optimal cutoff value for each immune-nutritional parameter (Neut, Lymp, Mono, Plt, or SII) was selected according to the receiver operating characteristic (ROC) curve for overall survival (OS) with the maximal Youden index based on the sum of sensitivity and specificity $[17,18]$. The cutoff values for serum albumin and CRP were set at $3.5 \mathrm{~g} / \mathrm{dl}$ and $0.5 \mathrm{mg} / \mathrm{dl}$, respectively, with reference to the modified Glasgow Prognostic Score, which is regarded as a useful prognostic indicator in various malignancies $[19,20]$. OS and recurrence-free survival (RFS) were generated using the Kaplan-Meier method, and the differences between the two groups were assessed with the log-rank test. Parameters showing significance in univariate analyses were further assessed using multivariate Cox's models. We used two types of multivariate Cox's models. In one model (model \#1), Neut, Lymp, or Plt was separately incorporated as explanatory variables. In the other model (model \#2), SII was incorporated as an explanatory variable instead of Neut, Lymp, and Plt. Hazard ratios (HR) and 95\% confidence intervals $(\mathrm{CI})$ were subsequently calculated. A $p$ value $<0.05$ was considered to be significant. Statistical analyses were performed with the software package JMP software version 10 (JMP, Cary, NC, USA).

\section{Results}

\section{Clinical characteristics}

The clinicopathological characteristics of 447 patients are shown in Table 1 . The median age was 67 years (range 29-89), with 289 male (64.7\%) and 158 female patients $(35.3 \%)$. The median (range) values were 3690 (1250-15,850) for Neut, 1780 (570-4770) for Lymp, 330 (50-1400) for Mono, $22.5 \times 10^{4}\left(8.7 \times 10^{4}-57.0 \times 10^{4}\right)$ for Plt, and 474 (105-4455) for SII.

\section{ROC curve analysis}

The area under the curve (AUC) value showing the predictive power of SII for 5-year OS was 0.650, and the Youden index was 0.238. As shown in Fig. 1, the optimal cutoff value for preoperative SII was 395 (sensitivity $41.0 \%$, specificity $82.8 \%$ ). All patients were then divided into the high SII (SII $\geq 395)$ and low SII $($ SII < 395) groups. The optimal cutoff values of other preoperative CBC parameters for predicting 5-year OS are shown in Additional file 1: Figure S1 (3690 for Neut (AUC 0.612), 1860 for Lymp (AUC 0.587), 320 for Mono (AUC 0.523 ), and $27.2 \times 10^{4}$ for Plt (AUC 0.581)).

\section{Relationship between preoperative SII and clinicopathological factors}

The differences in clinicopathological characteristics between the high and low SII groups are shown in Table 1. Preoperative Neut, Lymp, Mono, and Plt were significantly higher $(p<0.001,<0.001,=0.008$, and $<0.001$, respectively), and BMI was significantly lower $(p=0.021)$ in the high SII group than in the low SII group. In addition, hypoalbuminemia (albumin $<3.5$ ), $\mathrm{pN}+$, positive lymphatic invasion, and undifferentiated adenocarcinoma were frequent among patients in the high SII group $(p=0.014$, $0.003,0.004$, and 0.022 , respectively). No significant differences were observed in age, sex, PS, comorbidities, tumor location, preoperative CEA, CA 19-9, and CRP, pT, or venous invasion between the two groups.

\section{Prognostic significance of preoperative SII}

Survival curves for OS stratified by preoperative SII and each CBC parameter (Neut, Lymp, Mono, and Plt) are shown in Fig. 2A and Additional file 2: Figure S2, respectively. The 5-year OS rate of the high SII group was $80.0 \%$, which was significantly worse than that $(92.7 \%)$ of the low SII group $(p<0.001)$. Univariate and multivariate survival analyses of OS are shown in Table 2 . In the univariate analysis, PS $\geq 2$, hypertension, heart disease, upper GC, CEA $\geq 5$, CA19-9 $\geq 37$, albumin $<3.5$, CRP $\geq 0.5$, pT4, pN+, positive lymphatic invasion, positive venous invasion, Neut $\geq 3690$, Lymp $<1860$, Plt $\geq 27.2 \times 10^{4}$, and SII $\geq 395$ correlated with poor OS. In multivariate Cox's model \#1, Neut $\geq$ 3690 (HR 1.97; 95\% CI 1.08-3.68; $p=0.027$ ), heart disease, $\mathrm{CRP} \geq 0.5, \mathrm{pT} 4$, and $\mathrm{pN}+$ were identified as independent risk factors for poor OS. In multivariate Cox's model \#2, SII $\geq 395$ (HR 2.95; 95\% CI 1.49-6.39; $p=0.001$ ), heart disease, $\mathrm{CRP} \geq 0.5, \mathrm{pT} 4$, and $\mathrm{pN}+$ were identified as independent risk factors for poor OS.

Similar to the results of analyses of OS, the 5-year RFS rate of the high SII group was $77.7 \%$, which was significantly worse than that $(90.2 \%)$ of the low SII group ( $p=0.001)$ (Fig. 2B). The multivariate Cox's model identified SII $\geq 395$ as an independent risk predictor of 5-year RFS (HR 2.36; 95\% CI 1.31-4.48; $p=0.004$ ) (Additional file 3: Table S1).

\section{Relationship between preoperative SII and the type of GC recurrence}

GC recurrence was detected in 51 out of 447 patients. Cumulative recurrence rates stratified by preoperative SII were examined according to the type of GC recurrence (peritoneal, hematogenous, and lymph node recurrence) (Fig. 3). Peritoneal recurrence was more frequent in the high SII group than in the low SII group $(p=0.028)$, whereas no significant difference was observed in the cumulative recurrence rate for hematogenous or lymph node recurrence between the high and low SII groups ( $p=0.248$ and 0.096, respectively).

\section{Discussion}

In the present study, we examined the clinical significance of preoperative SII to predict postoperative survival 
Table 1 Clinicopathological characteristics of the patients

\begin{tabular}{|c|c|c|c|c|c|}
\hline Variables & & All patients $(n=447)$ & SII $\geq 395(n=280)$ & SII < $395(n=167)$ & $p$ value \\
\hline \multirow[t]{2}{*}{ Age, years } & Median & 67 & 67 & 67 & 0.215 \\
\hline & Range & $29-89$ & $29-89$ & $39-89$ & \\
\hline \multirow[t]{2}{*}{ Sex } & Male & 289 & $176(62.9 \%)$ & $113(67.7 \%)$ & 0.302 \\
\hline & Female & 158 & $104(37.1 \%)$ & $54(32.3 \%)$ & \\
\hline \multirow[t]{2}{*}{$\mathrm{BMI}, \mathrm{kg} / \mathrm{m}^{2}$} & Median & 22.2 & 21.9 & 23.1 & $0.021^{*}$ \\
\hline & Range & $14.4-34.2$ & $14.4-34.2$ & $15.6-30.6$ & \\
\hline \multirow[t]{2}{*}{ PS } & 1 & 233 & $146(52.1 \%)$ & $87(52.1 \%)$ & 0.992 \\
\hline & $\geq 2$ & 214 & 134 (47.9\%) & 80 (47.9\%) & \\
\hline \multirow[t]{2}{*}{ Hypertension } & Presence & 114 & 77 (27.5\%) & $37(22.2 \%)$ & 0.210 \\
\hline & Absence & 333 & $203(72.5 \%)$ & $130(77.8 \%)$ & \\
\hline \multirow[t]{2}{*}{ Diabetes mellitus } & Presence & 64 & 35 (12.5\%) & $29(17.4 \%)$ & 0.155 \\
\hline & Absence & 383 & $245(87.5 \%)$ & $138(82.6 \%)$ & \\
\hline \multirow[t]{2}{*}{ Heart disease } & Presence & 50 & $30(10.7 \%)$ & $20(12.0 \%)$ & 0.682 \\
\hline & Absence & 397 & $250(89.3 \%)$ & $147(88.0 \%)$ & \\
\hline \multirow[t]{2}{*}{ Chronic renal failure } & Presence & 10 & $6(2.1 \%)$ & $4(2.4 \%)$ & 0.862 \\
\hline & Absence & 437 & 274 (97.9\%) & $163(97.6 \%)$ & \\
\hline \multirow[t]{2}{*}{ Tumor location } & Upper & 145 & $96(34.3 \%)$ & 49 (29.3\%) & 0.278 \\
\hline & Middle/lower & 302 & $184(65.7 \%)$ & $118(70.7 \%)$ & \\
\hline \multirow[t]{2}{*}{ CEA, ng/ml } & $<5$ & 390 & $240(85.7 \%)$ & $150(89.8 \%)$ & 0.202 \\
\hline & $\geq 5$ & 57 & $40(14.3 \%)$ & $17(10.2 \%)$ & \\
\hline \multirow[t]{2}{*}{ CA19-9, U/ml } & $<37$ & 422 & $261(93.2 \%)$ & $161(96.4 \%)$ & 0.143 \\
\hline & $\geq 37$ & 25 & 19 (6.8\%) & $6(3.6 \%)$ & \\
\hline \multirow[t]{2}{*}{ Albumin, g/dl } & $<3.5$ & 19 & $17(6.1 \%)$ & $2(1.2 \%)$ & $0.014^{*}$ \\
\hline & $\geq 3.5$ & 428 & $263(93.9 \%)$ & $165(98.8 \%)$ & \\
\hline \multirow[t]{2}{*}{ CRP, mg/dl } & $<0.5$ & 397 & $245(87.5 \%)$ & $152(91.0 \%)$ & 0.254 \\
\hline & $\geq 0.5$ & 50 & $35(12.5 \%)$ & $15(9.0 \%)$ & \\
\hline \multirow[t]{2}{*}{ Neutrophil count, cell/ $/ \mathrm{mm}^{3}$} & Median & 3690 & 4145 & 3060 & $<0.001^{*}$ \\
\hline & Range & $1250-15,850$ & $1250-15,850$ & $1420-7630$ & \\
\hline \multirow[t]{2}{*}{ Lymphocyte count, cell/ $/ \mathrm{mm}^{3}$} & Median & 1780 & 1630 & 2050 & $<0.001^{*}$ \\
\hline & Range & $570-4770$ & $570-4770$ & $1050-4640$ & \\
\hline \multirow[t]{2}{*}{ Monocyte count, cell/mm $\mathrm{mm}^{3}$} & Median & 330 & 340 & 310 & $0.008^{*}$ \\
\hline & Range & $50-1400$ & $50-1400$ & $100-750$ & \\
\hline \multirow[t]{2}{*}{ Platelet count, cell $/ \mathrm{mm}^{3} \times 10^{4}$} & Median & 225 & 245 & 190 & $<0.001^{*}$ \\
\hline & Range & $87-570$ & $570-117$ & $87-314$ & \\
\hline \multirow[t]{2}{*}{ pT } & pT1-3 & 399 & $248(88.6 \%)$ & $151(90.4 \%)$ & 0.539 \\
\hline & pT4 & 48 & $32(11.4 \%)$ & $16(9.6 \%)$ & \\
\hline \multirow[t]{2}{*}{$\mathrm{pN}$} & pNO & 323 & 189 (67.5\%) & $134(80.2 \%)$ & $0.003^{*}$ \\
\hline & $\mathrm{pN}+$ & 124 & 91 (32.5\%) & $33(19.8 \%)$ & \\
\hline \multirow[t]{2}{*}{ Lymphatic invasion } & Presence & 169 & 120 (42.9\%) & $49(29.3 \%)$ & $0.004^{*}$ \\
\hline & Absence & 278 & 160 (57.1\%) & $118(70.6 \%)$ & \\
\hline \multirow[t]{2}{*}{ Venous invasion } & Presence & 138 & 95 (33.9\%) & $43(25.7 \%)$ & 0.068 \\
\hline & Absence & 309 & 185 (66.1\%) & $124(74.3 \%)$ & \\
\hline \multirow[t]{2}{*}{ Tumor differentiation } & Differentiated & 231 & $133(47.5 \%)$ & $98(58.7 \%)$ & $0.022^{*}$ \\
\hline & Undifferentiated & 216 & 147 (52.5\%) & 69 (41.3\%) & \\
\hline
\end{tabular}

BMI body mass index, PS physical status, CEA carcinoembryonic antigen, CA19-9 cancer antigen 19-9, CRP C-reactive protein, SII systemic immune inflammation index

${ }^{*} p<0.05$ (significantly different between the high and low SIl groups) 


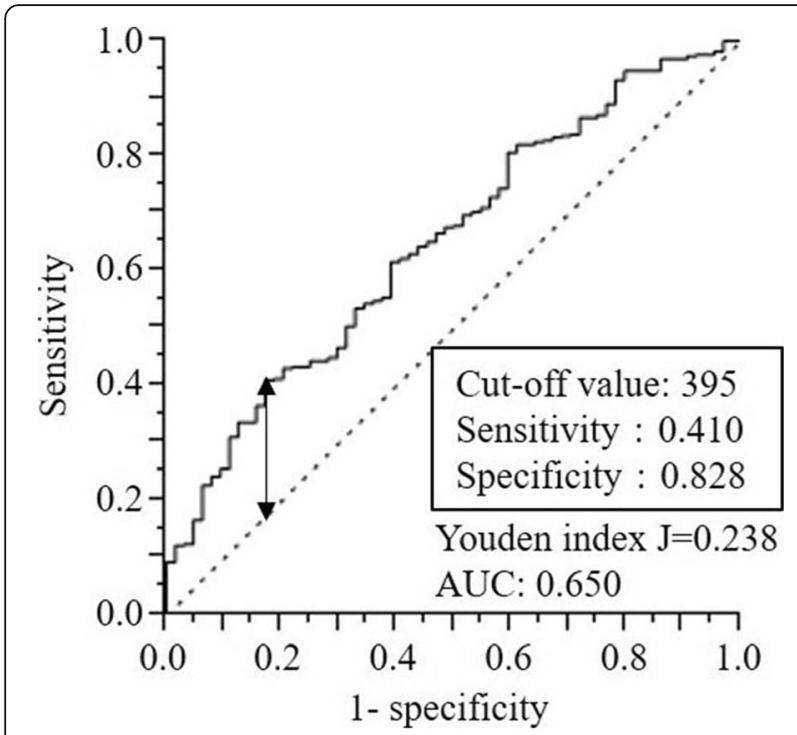

Fig. 1 ROC curve analysis of preoperative SII for predicting OS in patients with GC

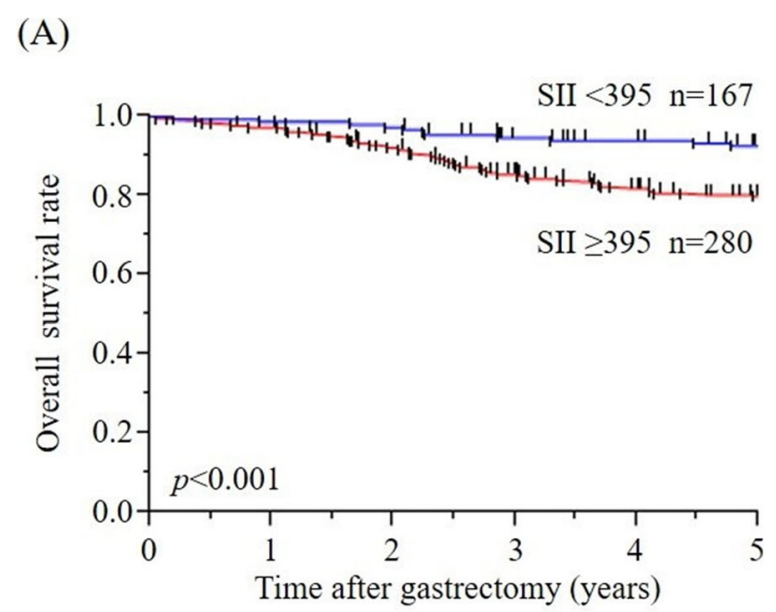

(B)

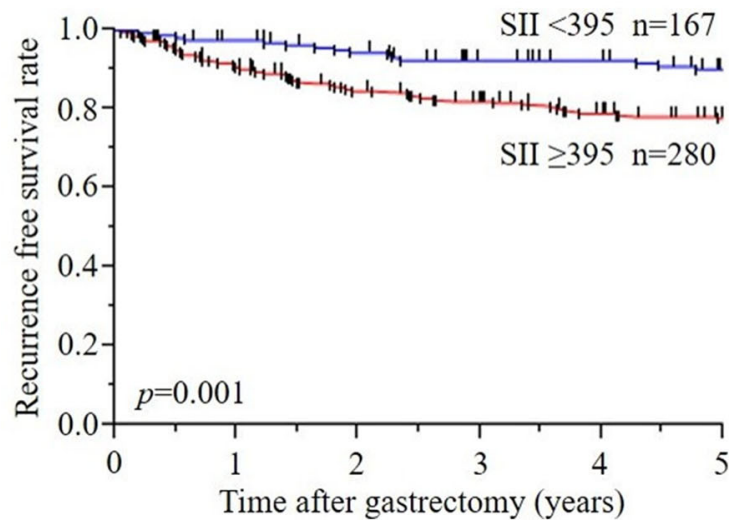

Fig. 2 Survival curves of patients stratified by preoperative SII. A OS. B RFS outcomes in GC. The optimal cutoff value of preoperative SII for predicting OS was set at 395 according to the ROC curve analysis. The results obtained demonstrated that SII, a combination of three CBC parameters (Neut, Lymp, and Plt), was an independent risk factor for poor OS and RFS as well as $\mathrm{pT}$ and $\mathrm{pN}$. Of special note was that high SII correlated with peritoneal recurrence. These results suggested that preoperative SII may contribute to perioperative precise care and adjuvant treatments for patients with GC undergoing curative gastrectomy.

In the present study, in addition to Neut, Lymp, Mono, and Plt, preoperative serum albumin and BMI correlated with preoperative SII. A relationship was previously suggested between obesity and chronic inflammation [21]; therefore, patients with high BMI may have a stronger inflammatory response. However, the present study showed that BMI was significantly lower in the high SII group. In cancer patients, inflammation is induced by inflammatory cytokines as cancer progresses, and, thus, patients with a high inflammatory response may lose weight [22]. In the present study, high SII correlated with low albumin levels, suggesting that cachexia had an influence on the results obtained. Hirahara et al. also reported that BMI was significantly lower in the high SII group [23].

Neutrophilia, lymphopenia, and thrombocytosis each affect a host's immune-inflammatory status and tumor progression and have been implicated in poor cancer survival [24-29]. In addition, several indexes calculated by combining these factors, such as neutrophil-tolymphocyte ratio, platelet-to-lymphocyte ratio, and monocyte-to-lymphocyte ratio, have been used to predict survival outcomes of GC [30-32]. Accordingly, high SII, resulting from neutrophilia, lymphopenia, and thrombocytosis, may also be a useful prognostic indicator. In the present study, univariate survival analyses showed that Neut, Lymp, and Plt were significant prognostic factors in patients with GC; however, the multivariate survival analysis (model \#1) only identified Neut $\geq 3690$ (HR 1.97; 95\% CI 1.08-3.68; $p=0.027$ ) as an independent risk factor of poor OS. The multivariate survival analysis (model \#2) also identified SII $\geq 395$ (HR 2.95; 95\% CI 1.49-6.39; $p=0.001$ ) as an independent risk factor of poor OS, with a higher HR and lower $p$ value than those of Neut in model \#1. The AUC value showing the predictive power of SII for OS (AUC 0.650) was higher than that (AUC 0.612) of Neut.

The negative impact of postoperative complications on survival outcomes has recently been clarified [33, 34]. Accordingly, worse OS may be attributed to a higher incidence of postoperative complications. However, in the present study, the incidence of postoperative complications of Clavien-Dindo grade II or higher in the high SII group was $13.9 \%$ (39/280), which was not significantly 
Table 2 Univariate and multivariate survival analyses for OS

\begin{tabular}{|c|c|c|c|c|c|c|c|c|}
\hline \multirow[t]{2}{*}{ Variables } & & \multirow{2}{*}{$\begin{array}{l}\text { All patients } \\
(n=447)\end{array}$} & \multicolumn{2}{|l|}{ Univariate } & \multicolumn{2}{|c|}{ Multivariate (model \#1) } & \multicolumn{2}{|c|}{ Multivariate (model \#2) } \\
\hline & & & 5-year OS (\%) & $p$ value & HR $(95 \% \mathrm{Cl})$ & $p$ value & HR $(95 \% \mathrm{Cl})$ & $p$ value \\
\hline \multirow[t]{2}{*}{ Age, years } & $<65$ & 184 & 86.9 & 0.262 & & & & \\
\hline & $\geq 65$ & 263 & 82.9 & & & & & \\
\hline \multirow[t]{2}{*}{ Sex } & Male & 289 & 84.9 & 0.846 & & & & \\
\hline & Female & 158 & 84.0 & & & & & \\
\hline \multirow[t]{2}{*}{$\mathrm{BMI}, \mathrm{kg} / \mathrm{m}^{2}$} & $<25$ & 353 & 84.3 & 0.701 & & & & \\
\hline & $\geq 25$ & 94 & 85.7 & & & & & \\
\hline \multirow[t]{2}{*}{ PS } & 1 & 233 & 89.4 & $0.004^{*}$ & 1 & 0.601 & 1 & 0.837 \\
\hline & $\geq 2$ & 214 & 78.8 & & $1.16(0.66-2.06)$ & & $1.06(0.61-1.86)$ & \\
\hline \multirow[t]{2}{*}{ Hypertension } & Presence & 114 & 76.2 & $<0.001^{*}$ & $1.50(0.85-2.58)$ & 0.158 & $1.50(0.87-2.54)$ & 0.147 \\
\hline & Absence & 333 & 87.4 & & 1 & & 1 & \\
\hline \multirow[t]{2}{*}{ Diabetes mellitus } & Presence & 64 & 79.5 & 0.177 & & & & \\
\hline & Absence & 383 & 85.4 & & & & & \\
\hline \multirow[t]{2}{*}{ Heart disease } & Presence & 50 & 70.0 & $<0.001^{*}$ & $2.52(1.22-4.99)$ & $0.014^{*}$ & $2.14(1.07-4.07)$ & $0.033^{*}$ \\
\hline & Absence & 397 & 86.4 & & & & & \\
\hline \multirow[t]{2}{*}{ Chronic renal failure } & Presence & 10 & 77.1 & 0.384 & & & & \\
\hline & Absence & 437 & 84.8 & & & & & \\
\hline \multirow[t]{2}{*}{ Tumor location } & Upper & 145 & 75.5 & $<0.001^{*}$ & $1.60(0.93-2.71)$ & 0.086 & $1.53(0.90-2.58)$ & 0.117 \\
\hline & Middle/lower & 302 & 88.7 & & 1 & & & \\
\hline \multirow[t]{2}{*}{ CEA, ng/ml } & $<5$ & 390 & 86.1 & $0.008^{*}$ & 1 & 0.243 & & 0.143 \\
\hline & $\geq 5$ & 57 & 72.4 & & $1.51(0.14-2.85)$ & & $1.68(0.83-3.15)$ & \\
\hline \multirow[t]{2}{*}{ CA19-9, U/ml } & $<37$ & 422 & 85.7 & $0.003^{*}$ & & 0.206 & & 0.328 \\
\hline & $\geq 37$ & 25 & 65.3 & & & & & \\
\hline \multirow[t]{2}{*}{ Albumin, $\mathrm{g} / \mathrm{dl}$} & $<3.5$ & 19 & 44.2 & $<0.001^{*}$ & $1.11(0.45-2.92)$ & 0.827 & $1.07(0.40-2.31)$ & 0.872 \\
\hline & $\geq 3.5$ & 428 & 86.4 & & & & & \\
\hline \multirow[t]{2}{*}{ CRP, mg/dl } & $<0.5$ & 397 & 87.0 & $<0.001^{*}$ & 1 & $0.021^{*}$ & & $0.021^{*}$ \\
\hline & $\geq 0.5$ & 50 & 65.5 & & $2.51(1.16-5.16)$ & & $2.45(1.15-4.94)$ & \\
\hline \multirow[t]{2}{*}{ Neutrophil count, cell/ $/ \mathrm{mm}^{3}$} & $<3690$ & 223 & 88.9 & $0.020^{*}$ & 1 & $0.027^{*}$ & & NA \\
\hline & $\geq 3690$ & 224 & 80.3 & & $1.9 /(1.08-3.68)$ & & & \\
\hline \multirow[t]{2}{*}{ Lymphocyte count, cell/ $/ \mathrm{mm}^{3}$} & $\geq 1860$ & 200 & 89.3 & $0.011^{*}$ & 1 & 0.242 & & NA \\
\hline & $<1860$ & 247 & 80.6 & & $1.41(0.80-2.56)$ & & & \\
\hline \multirow[t]{2}{*}{ Monocyte count, cell/ $/ \mathrm{mm}^{3}$} & $<320$ & 194 & 87.4 & 0.198 & & & & \\
\hline & $\geq 320$ & 253 & 82.4 & & & & & \\
\hline \multirow[t]{2}{*}{ Platelet count, cell $/ \mathrm{mm}^{3} \times 10^{4}$} & $<27.2$ & 338 & 87.6 & $0.003^{*}$ & 1 & 0.494 & & NA \\
\hline & $\geq 27.2$ & 109 & 75.2 & & $1.25(0.05-2.34)$ & & & \\
\hline \multirow[t]{2}{*}{ SII } & $<395$ & 167 & 92.7 & $<0.001^{*}$ & & NA & 1 & $0.001^{*}$ \\
\hline & $\geq 395$ & 280 & 80.0 & & & & $2.95(1.49-6.39)$ & \\
\hline pT & pT1-3 & 399 & 93.8 & $<0.001^{*}$ & 1 & $<0.001^{*}$ & 1 & $<0.001^{*}$ \\
\hline & pT4 & 48 & 57.8 & & $3.99(2.1 /-7.35)$ & & & \\
\hline $\mathrm{pN}$ & $\mathrm{pNO}$ & 323 & 93.7 & $<0.001^{*}$ & 1 & $<0.001^{*}$ & 1 & $<0.001^{*}$ \\
\hline & $\mathrm{pN}+$ & 124 & 60.8 & & $3.93(2.01-7.95)$ & & $4.02(2.10-7.93)$ & \\
\hline Lymphatic invasion & Presence & 169 & 71.3 & $<0.001^{*}$ & $1.35(0.69-2.68)$ & 0.386 & $1.18(0.61-2.32)$ & 0.626 \\
\hline & Absence & 278 & 92.7 & & & & & \\
\hline
\end{tabular}


Table 2 Univariate and multivariate survival analyses for OS (Continued)

\begin{tabular}{|c|c|c|c|c|c|c|c|c|}
\hline \multirow[t]{2}{*}{ Variables } & & \multirow{2}{*}{$\begin{array}{l}\text { All patients } \\
(n=447)\end{array}$} & \multicolumn{2}{|l|}{ Univariate } & \multicolumn{2}{|c|}{ Multivariate (model \#1) } & \multicolumn{2}{|c|}{ Multivariate (model \#2) } \\
\hline & & & 5-year OS (\%) & $p$ value & HR (95\% Cl) & $p$ value & HR (95\% Cl) & $p$ value \\
\hline \multirow[t]{2}{*}{ Venous invasion } & Presence & 138 & 71.2 & $<0.001^{*}$ & $1.13(0.65-1.97)$ & 0.675 & $1.22(0.70-2.14)$ & 0.475 \\
\hline & Absence & 309 & 90.3 & & & & & \\
\hline \multirow[t]{2}{*}{ Tumor differentiation } & Differentiated & 231 & 87.3 & 0.148 & & & & \\
\hline & Undifferentiated & 216 & 81.8 & & & & & \\
\hline
\end{tabular}

OS overall survival, $B M I$ body mass index, PS physical status, CEA carcinoembryonic antigen, CA19-9 cancer antigen 19-9, CRP C-reactive protein, S/l systemic immune inflammation index, $\mathrm{HR}$ hazard ratio, $\mathrm{Cl}$ confidence interval, $N A$ not applicable

* $p<0.05$ (significantly different between two groups)

different from that $(21 / 167,12.6 \%)$ in the low SII group $(p=0.684$, data not shown). Correlations between preoperative inflammatory indices and the occurrence of postoperative complications remain controversial $[35,36]$, and, thus, further studies are needed to confirm these relationships.

Previous studies demonstrated the negative impact of high preoperative SII on the survival outcomes of GC $[23,37,38]$; however, the cutoff values of SII differed between these studies. Wang et al. [37] reported that the optimal cutoff value of SII for predicting OS was 660 (AUC 0.612) according to the ROC curve analysis, and SII $\geq 660$ was an independent predictor of OS in GC patients. Hirahara et al. [23] showed that the optimal cutoff value of SII for predicting OS was 661.9 (AUC 0.584) according to the ROC curve analysis, and SII $\geq 661.9$ was an independent prognostic indicator in GC patients, particularly in the elderly population. In the present study, although an ROC curve analysis was also used, the optimal cutoff value of SII for predicting OS was 395, which was markedly lower than 600. Differences in the pStage of GC patients may affect SII cutoff values. Although Wang et al. only targeted pStage III GC patients who had undergone R0, R1, or R2, the present study examined pStage I, II, and III patients undergoing R0 [37]. Similar to the present results, Shi et al. only targeted patients with pStage I-III GC who had undergone R0 and demonstrated that the optimal SII cutoff value was 320 (AUC 0.64) and that SII > 320 was an independent prognostic indicator in these patients [38]. Therefore, further studies are needed to validate the optimal cutoff value of SII.

The present study demonstrated that preoperative SII was a risk factor for poor RFS independent of $\mathrm{pT}$ and $\mathrm{pN}$ and that SII $\geq 395$ correlated with GC recurrence, particularly peritoneal recurrence. To the best of our knowledge, this is the first study to demonstrate the impact of high SII on the specific recurrence pattern of GC. A previous study showed that neutrophils promoted the migration and invasion of GC cells by activating the ERK pathway and inducing epithelial-mesenchymal transition [27]. Other studies indicated that lymphopenia and thrombocytosis were predictive factors for peritoneal dissemination [39, 40]. In addition, Nakamura et al. [41] reported that the preoperative neutrophil-to-lymphocyte ratio was a significant independent predictor of the presence of peritoneal metastasis during staging laparoscopy in patients with advanced GC. Since high SII results from neutrophilia, lymphopenia, and thrombocytosis, it may also be a useful predictor of peritoneal recurrence. In the present study, from a pathological viewpoint, $\mathrm{pN}+$ and undifferentiated adenocarcinoma were often observed in the high SII group. Peritoneal recurrence was also frequently detected in patients with $\mathrm{pN}+(\mathrm{pN}+, 25 / 124 ; \mathrm{pN}-, 3 / 320$; $p<0.001$ ) and undifferentiated adenocarcinoma (differentiated type, 10/231; undifferentiated type, 18/216; $p=$ 0.081 ); therefore, the incidence of peritoneal recurrence may be high in patients with high SII.

According to JGCTG, the current indication of postoperative adjuvant chemotherapy is assessed only by pStage ( $\mathrm{pT}$ and $\mathrm{pN})$. However, the present results suggest that patients with high preoperative SII may also be considered for adjuvant chemotherapy. In Western countries, perioperative chemotherapy (preoperative plus postoperative FLOT) is the standard treatment [42, 43]. Although postoperative adjuvant chemotherapy alone is the standard treatment in Eastern Asia, its effects are inadequate in many cases; therefore, patients with poor prognostic factors, such as high SII, may be good candidates for neoadjuvant chemotherapy. Perioperative interventions, such as immunonutrition, may be another treatment option for improving the survival outcomes of patients with high SII. However, there is currently no evidence to show that perioperative immunonutrition actually improves the long-term outcomes of GC patients. It also currently remains unclear whether preoperative immunonutrition reduces morbidity rates after gastrectomy for GC [44-46]. Xin et al. [47] has recently shown by a systematic review and a meta-analysis that enteral nutrition feeding tube support is an essential intervention to elevate patients' immunity, depress levels of inflammation, and reduce the risk of complications after gastrectomy for GC. Therefore, further research and the development of novel treatment methods that fundamentally suppress cancer-induced inflammation and boost host immunity are desired. 


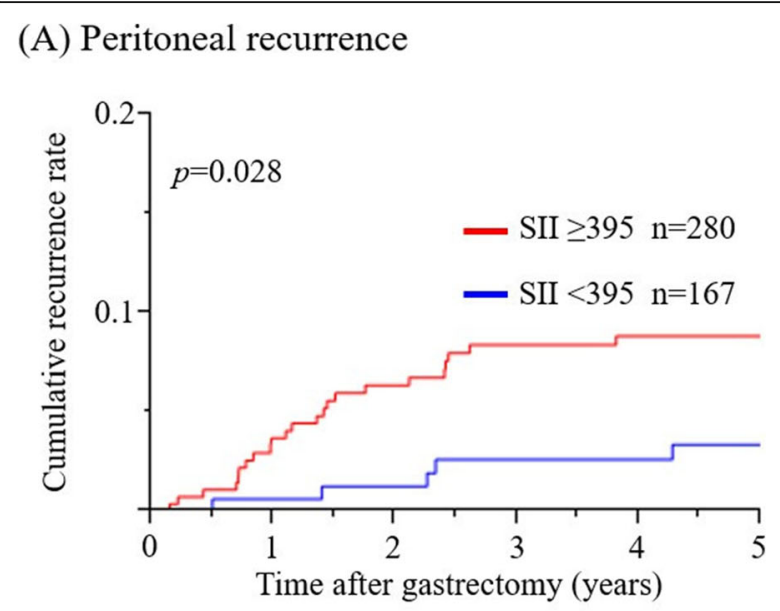

(B) Lymph node recurrence

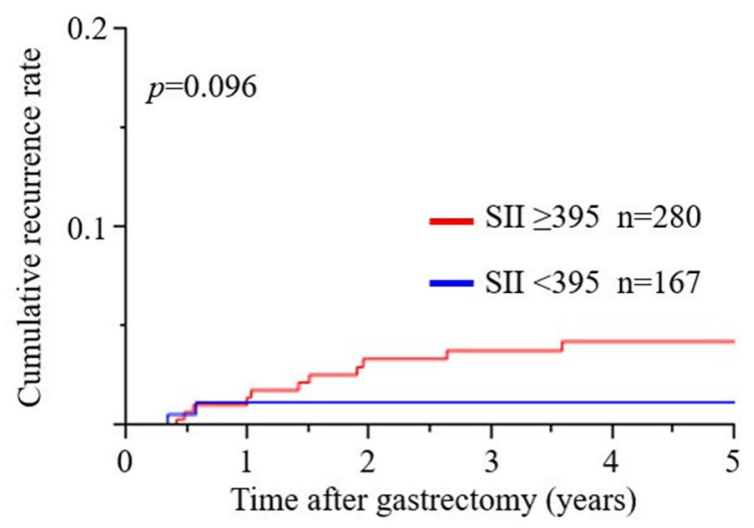

(C) Hematogenous recurrence

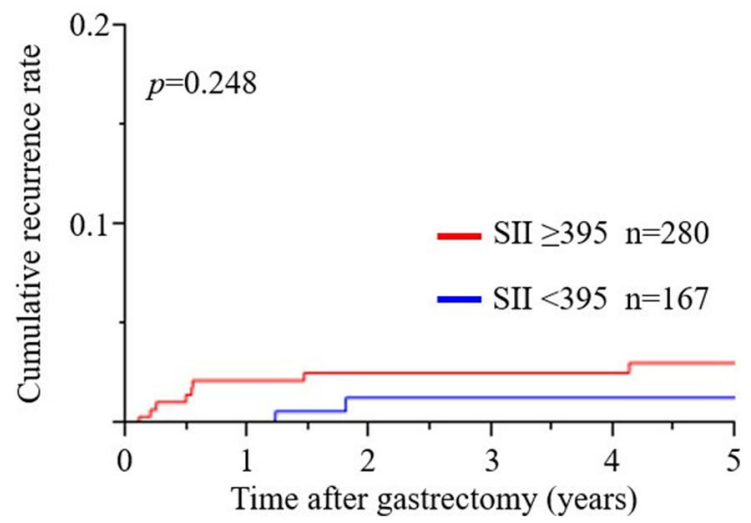

Fig. 3 Cumulative recurrence rate for each recurrence pattern stratified by preoperative SII. A Peritoneal recurrence. B Lymph node recurrence. $\mathbf{C}$ Hematogenous recurrence

The present study had several limitations. It was a retrospective study with a small sample size from one institution, which may have limited its statistical power and generated statistical biases. Furthermore, since the cutoff values of Neut, Lymp, Mono, Plt, and SII were only calculated by a mathematical method, further validations are needed to confirm whether these values are clinically meaningful and applicable to other cohorts. In addition, the present study only examined $\mathrm{CBC}$ parameters; however, serum immune-nutritional markers may also be useful predictors of survival outcomes in GC. Dynamic changes in the host's immune-inflammatory status during the perioperative period may provide more important information about survival outcomes, but the present study failed to evaluate dynamic changes in the SII values [30]. Relationships between tumor microenvironment and the mechanisms of immune dysfunction should be uncovered to develop promising immunotherapy and improve survival outcomes of GC patients [48-50]; however, no molecular biological examinations have been done in this study. Nevertheless, the present study clearly demonstrated the novel potential of preoperative SII for predicting postoperative survival outcomes and recurrence patterns in GC over that of each CBC parameter (Neut, Lymp, Mono, and Plt). The results of the present study and the optimal cutoff value of SII need to be validated in further studies with large sample sizes in order to establish a novel perioperative care system according to preoperative SII levels.

\section{Conclusion}

Preoperative SII may be a useful predictor of postoperative survival outcomes in GC. Appropriate postoperative adjuvant treatments and the meticulous surveillance of GC relapse, particularly peritoneal dissemination, are necessary for patients with SII $\geq 395$ even after curative gastrectomy.

\section{Abbreviations}

AUC: Area under the curve; BMl: Body mass index; CA19-9: Cancer antigen 19-9; CBC: Complete blood count; CEA: Carcinoembryonic antigen; Cl: Confidence interval; CT: Computed tomography; GC: Gastric cancer; HR: Hazard ratio; JGCTG: Japanese Gastric Cancer Treatment Guidelines; Lymp: Lymphocyte; Mono: Monocyte; Neut: Neutrophil; OS: Overall survival; Plt: Platelet; PS: Physical status; RFS: Recurrence-free survival; ROC: Receiver operating characteristic; SII: Systematic immune-inflammation index

\section{Supplementary Information}

The online version contains supplementary material available at https://doi. org/10.1186/s12957-021-02286-3.

Additional file 1: Figure S1. ROC curve analysis of preoperative each CBC parameter for predicting OS in patients with GC. (A) Neutrophil, (B) Lymphocyte, (C) Monocyte, (D) Platelet.

Additional file 2: Figure S2. OS curves of the patients stratified $C B C$ parameter. (A) Neutrophil, (B) Lymphocyte, (A) Monocyte, (A) Platelet.

Additional file 3: Table S1. Univariate and multivariate survival analyses for RFS. 


\section{Authors' contributions}

$\mathrm{HI}$ and TK1 contributed to the study conception and design. $\mathrm{HI}$ acquired the data. HI, TK1, TK2, HK, AS, KO, and HF contributed to the analysis and interpretation of the data. HI and TK1 wrote the manuscript. EO made the critical revision. All authors have read and approved the final manuscript.

\section{Funding}

No funding.

\section{Availability of data and materials}

The datasets used and/or analyzed during the current study are available from the corresponding author on reasonable request.

\section{Declarations}

\section{Ethics approval and consent to participate}

All procedures performed in studies involving human participants were in accordance with the ethical standards of the institutional and/or national research committee and with the 1964 Helsinki Declaration and its later amendments or comparable ethical standards. This retrospective study was approved by the Medical Ethics Review Committee of the Kyoto Prefectural University of Medicine (approval no. ERB-C-1327). It was determined to be a retrospective analysis of de-identified data, and written informed consent was waived for the individual participants included in the study in accordance with the standards of the Kyoto Prefectural University of Medicine Institutional Medical Ethics Review Committee.

\section{Consent for publication}

Not applicable.

\section{Competing interests}

The authors declare that they have no competing interests.

Received: 30 November 2020 Accepted: 3 June 2021

Published online: 12 June 2021

\section{References}

1. Bray F, Ferlay J, Soerjomataram I, Siegel RL, Torre LA, Jemal A. Global cancer statistics 2018: GLOBOCAN estimates of incidence and mortality worldwide for 36 cancers in 185 countries. CA Cancer J Clin. 2018;68(6):394-424. https://doi.org/10.3322/caac.21492.

2. Diakos $\mathrm{Cl}$, Charles KA, McMillan DC, Clarke SJ. Cancer-related inflammation and treatment effectiveness. Lancet Oncol. 2014;15(11):e493-503. https:// doi.org/10.1016/S1470-2045(14)70263-3.

3. Hanahan D, Weinberg RA. Hallmarks of cancer: the next generation. Cell. 2011;144(5):646-74. https://doi.org/10.1016/j.cell.2011.02.013.

4. Guner A, Kim SY, Yu JE, Min IK, Roh YH, Roh C, et al. Parameters for predicting surgical outcomes for gastric cancer patients: simple is better than complex. Ann Surg Oncol. 2018;25(11):3239-47. https://doi.org/10.124 5/s10434-018-6684-2

5. Feng F, Zheng G, Wang Q, Liu S, Liu Z, Xu G, et al. Low lymphocyte count and high monocyte count predicts poor prognosis of gastric cancer. BMC Gastroenterol. 2018;18(1):148. https://doi.org/10.1186/s12876-018-0877-9.

6. Oh SE, Seo JE, An JY, Lee JH, Sohn TS, Bae JM, et al. Prognostic impact of increased perioperative platelet count in gastric cancer patients. I Surg Res. 2019;242:296-303. https://doi.org/10.1016/j.jss.2019.04.052.

7. Ishibashi Y, Tsujimoto H, Hiraki S, Kumano I, Yaguchi Y, Horiguchi H, et al. Prognostic value of preoperative systemic immunoinflammatory measures in patients with esophageal cancer. Ann Surg Oncol. 2018;25(11):3288-99. https://doi.org/10.1245/s10434-018-6651-y.

8. Chen JH, Zhai ET, Yuan YJ, Wu KM, Xu JB, Peng JJ, et al. Systemic immuneinflammation index for predicting prognosis of colorectal cancer. World J Gastroenterol. 2017;23(34):6261-72. https://doi.org/10.3748/wjg.v23.134.6261.

9. Aziz MH, Sideras K, Aziz NA, Mauff K, Haen R, Roos D, et al. The systemicimmune-inflammation index independently predicts survival and recurrence in resectable pancreatic cancer and its prognostic value depends on bilirubin levels: a retrospective multicenter cohort study. Ann Surg. 2019; 270(1):139-46. https://doi.org/10.1097/SLA.0000000000002660.

10. Japanese Gastric Cancer Treatment Guidelines 2018 (5th edn). Gastric Cancer. 2021;24(1):1-21. https://doi.org/10.1007/s10120-020-01042-y.
11. Brierley JDGM, Wittekind C. TNM classification of malignant tumours. Union for International Cancer Control. 8th ed. Wiley; 2017;8(1):1-253. https://www. uicc.org/resources/tnm.

12. Dindo D, Demartines N, Clavien PA. Classification of surgical complications: a new proposal with evaluation in a cohort of 6336 patients and results of a survey. Ann Surg. 2004;240(2):205-13. https://doi.org/10.1097/01.sla.0000133 083.54934.ae.

13. Clavien PA, Barkun J, de Oliveira ML, Vauthey JN, Dindo D, Schulick RD, et al. The Clavien-Dindo classification of surgical complications: five-year experience. Ann Surg. 2009;250(2):187-96. https://doi.org/10.1097/SLA.0b013 e3181b13ca2.

14. Sakuramoto S, Sasako M, Yamaguchi T, Kinoshita T, Fujii M, Nashimoto A, et al. Adjuvant chemotherapy for gastric cancer with $\mathrm{S}-1$, an oral fluoropyrimidine. N Engl J Med. 2007;357(18):1810-20. https://doi.org/10.1 056/NEJMoa072252.

15. Shitara K, Chin K, Yoshikawa T, Katai H, Terashima M, Ito S, et al. Phase II study of adjuvant chemotherapy of S-1 plus oxaliplatin for patients with stage III gastric cancer after D2 gastrectomy. Gastric Cancer. 2017;20(1):17581. https://doi.org/10.1007/s10120-015-0581-1.

16. Bang YJ, Kim YW, Yang HK, Chung HC, Park YK, Lee KH, et al. Adjuvant capecitabine and oxaliplatin for gastric cancer after D2 gastrectomy (CLAS SIC): a phase 3 open-label, randomised controlled trial. Lancet. 2012; 379(9813):315-21. https://doi.org/10.1016/S0140-6736(11)61873-4.

17. Fluss $R$, Faraggi D, Reiser B. Estimation of the Youden Index and its associated cutoff point. Biom J. 2005;47(4):458-72. https://doi.org/10.1002/ bimi.200410135.

18. Perkins NJ, Schisterman EF. The inconsistency of "optimal" cutpoints obtained using two criteria based on the receiver operating characteristic curve. Am J Epidemiol. 2006;163(7):670-5. https://doi.org/10.1093/aje/ kwj063.

19. Hirashima K, Watanabe M, Shigaki H, Imamura Y, Ida S, Iwatsuki M, et al. Prognostic significance of the modified Glasgow prognostic score in elderly patients with gastric cancer. J Gastroenterol. 2014;49(6):1040-6. https://doi org/10.1007/s00535-013-0855-5

20. Urabe M, Yamashita H, Watanabe T, Seto Y. Comparison of prognostic abilities among preoperative laboratory data indices in patients with resectable gastric and esophagogastric junction adenocarcinoma. World J Surg. 2018;42(1):185-94. https://doi.org/10.1007/s00268-017-4146-9.

21. Hotamisligil GS. Inflammation and metabolic disorders. Nature. 2006; 444(7121):860-7. https://doi.org/10.1038/nature05485.

22. Amitani $\mathrm{M}$, Asakawa A, Amitani $\mathrm{H}$, Inui A. Control of food intake and muscle wasting in cachexia. Int J Biochem Cell Biol. 2013;45(10):2179-85. https://doi. org/10.1016/.jbiocel.2013.07.016.

23. Hirahara N, Tajima Y, Matsubara T, Fujii Y, Kaji S, Kawabata Y, Hyakudomi R, Yamamoto T, Uchida Y, Taniura T. Systemic immune-inflammation index predicts overall survival in patients with gastric cancer: a propensity scorematched analysis. J Gastrointest Surg. 2021:25(5):1124-33. https://doi.org/1 0.1007/s1 1605-020-04710-7.

24. Quigley DA, Kristensen V. Predicting prognosis and therapeutic response from interactions between lymphocytes and tumor cells. Mol Oncol. 2015; 9(10):2054-62. https://doi.org/10.1016/j.molonc.2015.10.003.

25. Dunn GP, Old $L$, Schreiber RD. The immunobiology of cancer immunosurveillance and immunoediting. Immunity. 2004:21 (2):137-48. https://doi.org/10.1016/j.immuni.2004.07.017.

26. Uribe-Querol E, Rosales C. Neutrophils in cancer: two sides of the same coin. J Immunol Res. 2015;2015:983698.

27. Zhang W, Gu J, Chen J, Zhang P, Ji R, Qian H, et al. Interaction with neutrophils promotes gastric cancer cell migration and invasion by inducing epithelial-mesenchymal transition. Oncol Rep. 2017;38(5):2959-66. https://doi.org/10.3892/or.2017.5942.

28. Kay HD, Smith DL. Regulation of human lymphocyte-mediated natural killer (NK) cell activity. I. Inhibition in vitro by peripheral blood granulocytes. J Immunol. 1983;130(1):475-83.

29. el-Hag A, Clark RA. Immunosuppression by activated human neutrophils. Dependence on the myeloperoxidase system. J Immunol. 1987:139(7):2406-13.

30. Kim EY, Song KY. The preoperative and the postoperative neutrophil-tolymphocyte ratios both predict prognosis in gastric cancer patients. World Surg Oncol. 2020;18(1):293. https://doi.org/10.1186/s12957-020-02059-4.

31. Zhang X, Zhao W, Yu Y, Qi X, Song L, Zhang C, et al. Clinicopathological and prognostic significance of platelet-lymphocyte ratio (PLR) in gastric 
cancer: an updated meta-analysis. World J Surg Oncol. 2020;18(1):191. https://doi.org/10.1186/s12957-020-01952-2.

32. Chen L, Hao Y, Zhu L, Li S, Zuo Y, Zhang Y, et al. Monocyte to lymphocyte ratio predicts survival in patients with advanced gastric cancer undergoing neoadjuvant chemotherapy. Onco Targets Ther. 2017;10:4007-16. https:// doi.org/10.2147/OTT.S140118.

33. Kubota T, Hiki N, Sano T, Nomura S, Nunobe S, Kumagai K, et al. Prognostic significance of complications after curative surgery for gastric cancer. Ann Surg Oncol. 2014;21(3):891-8. https://doi.org/10.1245/s10434-013-3384-9.

34. Tokunaga M, Tanizawa Y, Bando E, Kawamura T, Terashima M. Poor survival rate in patients with postoperative intra-abdominal infectious complications following curative gastrectomy for gastric cancer. Ann Surg Oncol. 2013; 20(5):1575-83. https://doi.org/10.1245/s10434-012-2720-9.

35. Platt JJ, Ramanathan ML, Crosbie RA, Anderson JH, McKee RF, Horgan $P G$, et al. C-reactive protein as a predictor of postoperative infective complications after curative resection in patients with colorectal cancer. Ann Surg Oncol. 2012;19(13):4168-77. https://doi.org/10.1245/s10434012-2498-9.

36. Sasahara M, Kanda M, Ito S, Mochizuki $Y$, Teramoto $H$, Ishigure $K$, et al. The preoperative prognostic nutritional index predicts short-term and long-term outcomes of patients with stage II/III gastric cancer: analysis of a multiinstitution dataset. Dig Surg. 2020;37(2):135-44. https://doi.org/10.1159/0004 97454.

37. Wang K, Diao F, Ye Z, Zhang X, Zhai E, Ren $\mathrm{H}$, et al. Prognostic value of systemic immune-inflammation index in patients with gastric cancer. Chin J Cancer. 2017;36(1):75. https://doi.org/10.1186/s40880-017-0243-2.

38. Shi $\mathrm{H}$, Jiang $\mathrm{Y}$, Cao H, Zhu H, Chen B, Ji W. Nomogram based on systemic immune-inflammation index to predict overall survival in gastric cancer patients. Dis Markers. 2018:2018:1787424.

39. Chen XD, Mao CC, Wu RS, Zhang WT, Lin J, Sun XW, et al. Use of the combination of the preoperative platelet-to-lymphocyte ratio and tumor characteristics to predict peritoneal metastasis in patients with gastric cancer. PLoS One. 2017;12(4):e0175074. https://doi.org/10.1371/journal.pone. 0175074.

40. Ohi M, Mori K, Toiyama Y, Mohri Y, Okigami M, Yasuda H, et al. Preoperative prediction of peritoneal metastasis in gastric cancer as an indicator for neoadjuvant treatment. Anticancer Res. 2015;35(6):3511-8.

41. Nakamura N, Kinami S, Fujii Y, Miura S, Fujita J, Kaida D, et al. The neutrophi//ymphocyte ratio as a predictor of peritoneal metastasis during staging laparoscopy for advanced gastric cancer: a retrospective cohort analysis. World J Surg Oncol. 2019;17(1):108. https://doi.org/10.1186/s12957019-1651-3.

42. Lorenzen S, Pauligk C, Homann N, Schmalenberg H, Jäger E, Al-Batran SE. Feasibility of perioperative chemotherapy with infusional 5-FU, leucovorin, and oxaliplatin with (FLOT) or without (FLO) docetaxel in elderly patients with locally advanced esophagogastric cancer. Br J Cancer. 2013;108(3):51926. https://doi.org/10.1038/bjc.2012.588.

43. Al-Batran SE, Homann N, Pauligk C, Illerhaus G, Martens UM, Stoehlmacher J, et al. Effect of neoadjuvant chemotherapy followed by surgical resection on survival in patients with limited metastatic gastric or gastroesophageal junction cancer: The AIO-FLOT3 Trial. JAMA Oncol. 2017;3(9):1237-44. https://doi.org/10.1001/jamaoncol.2017.0515.

44. Okamoto Y, Okano K, Izuishi K, Usuki H, Wakabayashi H, Suzuki Y. Attenuation of the systemic inflammatory response and infectious complications after gastrectomy with preoperative oral arginine and omega-3 fatty acids supplemented immunonutrition. World J Surg. 2009; 33(9):1815-21. https://doi.org/10.1007/s00268-009-0140-1.

45. Fujitani K, Tsujinaka T, Fujita J, Miyashiro I, Imamura H, Kimura Y, et al. Prospective randomized trial of preoperative enteral immunonutrition followed by elective total gastrectomy for gastric cancer. Br J Surg. 2012; 99(5):621-9. https://doi.org/10.1002/bjs.8706

46. Claudino MM, Lopes JR, Rodriques VD, de Pinho NB, Martucci RB. Postoperative complication rate and survival of patients with gastric cancer undergoing immunonutrition: a retrospective study. Nutrition. 2020;70: 110590. https://doi.org/10.1016/..nut.2019.110590.

47. Xin F, Mzee SAS, Botwe G, He H, Zhiyu S, Gong C, et al. Short-term evaluation of immune levels and nutritional values of EN versus PN in gastric cancer: a systematic review and a meta-analysis. World J Surg Oncol. 2019;17(1):114. https://doi.org/10.1186/s12957-019-1658-9.

48. Li L, Huang S, Yao Y, Chen J, Li J, Xiang X, et al. Follistatin-like 1 (FSTL1) is a prognostic biomarker and correlated with immune cell infiltration in gastric cancer. World J Surg Oncol. 2020;18(1):324. https://doi.org/10.1186/s12957020-02070-9.

49. Kim JW, Nam KH, Ahn SH, Park DJ, Kim HH, Kim SH, et al. Prognostic implications of immunosuppressive protein expression in tumors as well as immune cell infiltration within the tumor microenvironment in gastric cancer. Gastric Cancer. 2016;19(1):42-52. https://doi.org/10.1007/ s10120-014-0440-5.

50. Lazăr DC, Avram MF, Romoșan I, Cornianu M, Tăban S, Goldiș A. Prognostic significance of tumor immune microenvironment and immunotherapy: novel insights and future perspectives in gastric cancer. World J Gastroenterol. 2018;24(32):3583-616. https://doi.org/10.3 748/wjg.v24.i32.3583.

\section{Publisher's Note}

Springer Nature remains neutral with regard to jurisdictional claims in published maps and institutional affiliations.
Ready to submit your research? Choose BMC and benefit from:

- fast, convenient online submission

- thorough peer review by experienced researchers in your field

- rapid publication on acceptance

- support for research data, including large and complex data types

- gold Open Access which fosters wider collaboration and increased citations

- maximum visibility for your research: over $100 \mathrm{M}$ website views per year

At BMC, research is always in progress.

Learn more biomedcentral.com/submissions 